\title{
Editorial
}

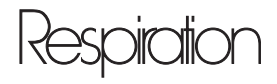

\section{To Remember and to Motivate: The Chris Bolliger Award}

Still inconceivable to us, Chris T. Bolliger died in 2012. From the mid-1980s until his death, Chris was an innovator and motivator in the field of pulmonology, in particular interventional pulmonology. In 1998, Chris took over the editorship of Respiration following a year of being joint editor with Prof. Herzog [1]. He changed the content of the journal in an inventive and deliberate manner. By adding review series and new sections (technical notes, eye catchers, and guidelines), he developed the journal, together with the team of Karger, into one of the wellrespected journals in the field of pulmonary medicine.

For his activities and scientific input, he has received countless awards and recognition. In 2010, for example, he was awarded the Lifetime Achievement Certificate of the World Association of Bronchology and Interventional Pulmonology during their World Congress in Budapest, Hungary.

We felt it a logical step to introduce an award named after him. After discussing this idea with the publisher and the associated editors, it came down to a few practical questions: who should the annual award be given to? How do we select the reviewers? Should it depend on award submissions or degree of familiarity of a paper? In which section should the award be placed and where do we perform the award ceremony? During the discussion of these points, we kept Chris' visions in mind. Chris was a great researcher and mentor. Therefore, the award should be given to somebody presenting actual science in an evidence-based approach. It was therefore clear that the award should only be given for an original article.

Chris was a visionary editor of the journal. Logically, the prize should be given to somebody who published his work in the journal. So the next point was set. How often and where?
In addition to his clinical and research activities, he was active politically and helped form the image of modern pulmonology. He served for the European Respiratory Society in several positions, including head of the Clinical Assembly. In this position, Chris developed and strengthened the assembly and succeeded in uniting the diverse interests within it. Thus, the annual congress of the European Respiratory Society seemed the ideal scenario for the award reception at the Karger Booth in the exhibition area. Everybody agreed to award the prize annually.

Last but not least, who should be awarded? Only a brief discussion was necessary for this last point. It is an award for scientists, so an appropriate way to assess who should receive the award is to use the other scientists and readers of the article as assessors. In order to calculate the impact factor of a journal, the citation of every article is counted. For the calculation for the current year, the 2 last years of publications are used. The number of citations depends on the quality and content of the article. Therefore, the decision was made to give the award to the original article, which was most cited in the previous year.

In 2017, during the annual congress of the ERS in Milan, we will hand over the award to the first author of the most-cited original article in Respiration for the years 2014 and 2015. We hope to see you all at the reception, to honor the awardees and to remember Chris.

On behalf of all members of the editorial board Felix J.F. Herth, Heidelberg

\section{References}

1 Herth FJF: Let's move on! Respiration 2013;85:177. 